\title{
Freeze-Thaw Stability Analysis of the High-Ice Content Soil-Rock Cutting Slope: A Case Study in Oroqen Autonomous Banner, North China
}

\author{
Yuxia Zhao $\mathbb{D}^{1},{ }^{1}$ Jun Feng $\mathbb{D}^{\mathbb{2}},{ }^{2}$ Kangqi Liu $\mathbb{D}^{1},{ }^{1}$ Qi Wu $\mathbb{D}^{3},{ }^{3}$ Liqun Wang $\mathbb{D}^{4},{ }^{4}$ and Hongyan Liu $\mathbb{D}^{1}$ \\ ${ }^{1}$ School of Engineering and Technology, China University of Geosciences (Beijing), Beijing 100083, China \\ ${ }^{2}$ School of Airport Engineering and Transportation Management, Civil Aviation Flight University of China, \\ Guanghan 618307, China \\ ${ }^{3}$ School of Civil Engineering, Henan Vocational University of Science and Technology, Zhoukou 466000, China \\ ${ }^{4}$ Beijing Municipal Road \& Bridge (Group) Co., Ltd., Beijing 100009, China
}

Correspondence should be addressed to Hongyan Liu; zyxcugb@sina.com

Received 4 September 2020; Revised 19 September 2020; Accepted 26 September 2020; Published 21 October 2020

Academic Editor: Chun Zhu

Copyright (C) 2020 Yuxia Zhao et al. This is an open access article distributed under the Creative Commons Attribution License, which permits unrestricted use, distribution, and reproduction in any medium, provided the original work is properly cited.

\begin{abstract}
National Highway 332 (referred to as line 332) is the most convenient way for the forest areas (Oroqen Autonomous Banner, etc.) in northern China. This area is located in the high-latitude permafrost regions of the Daxing'anling Mountains. The section of line 332 from Ali River to Kubuchun Forest Farm is $116 \mathrm{~km}$ long, and the permafrost section is $7.45 \mathrm{~km}$. Part of the section, K105+700$\mathrm{K} 105+800$, is a road cutting slope with high ice content, and it is also our research object. The slope to be studied is difficult to construct and has high landslide risk, so we arranged thirty-five temperature sensors, four moisture sensors, and eighteen landmarks on the slope to grasp the dynamic changes of the slope under freeze-thaw conditions. After collecting the continuous data of temperature, moisture, settlement, and deformation of the slope, we found that the slope was undergoing freeze-thaw cycles, and the shallow slippage of the slope reached $6.811 \mathrm{~cm}$ in 2019 . Besides, the drilled core samples were tested in the laboratory and relevant parameters were obtained. Then, the slope stability was numerically simulated in ABAQUS numerical simulation software. After two hundred freeze-thaw cycles, the slope safety factor reached 0.997 , indicating that the slope was in a state of extreme equilibrium, so the potential freeze-thaw disasters must be considered during road operation, and higher requirements for the permanent protection of slopes should also be put forward. The study can provide guidance for the design and construction of road cutting slope in the permafrost regions of the Daxing'anling Mountains.
\end{abstract}

\section{Introduction}

With the increase in the construction of slope engineering structures, the harm and economic losses caused by landslides have become more and more serious [1]. In cold regions, slope instability is closely related to freeze-thaw cycles [2]. Research on the stability of slopes under freezethaw cycles has been carried out by researchers at home and abroad tirelessly. Related experiments have shown that freeze-thaw cycles and dry-wet alternation can deteriorate the physical and mechanical properties of rock and soil, cause fatigue damage to slopes, and affect the slope stability $[3,4]$. Through experiments, Liu et al. concluded that the perme- ability of sandstone in the Ordos Basin shows an exponential increase with the increase of porosity [5]. Moreover, as the porosity of the slope increases, irreversible freeze-thaw damage occurs to the slope, and the closer the slope foot, the greater the damage [6]. Wang et al. concluded that when the freeze-thaw cycles and dry-wet alternation increase, the slope safety factor decreases, especially for mining slopes [7]. In the early period of the freeze-thaw cycle, the slope stability decreases the most.

Cui et al. carried out the stability analysis of the seasonally frozen soil slope in the Baotou area of Inner Mongolia [8]. To investigate the freeze-thaw erosion process of vegetation slopes in seasonally frozen soil regions, Rui et al. 
conducted on-site freeze-thaw tests in the frozen soil testing ground of Kitami Institute of Technology [9]. Liu et al. studied the instability mechanism of the silty clay slope on the highway from Tongjiang to Sanya and the corresponding vegetation protection measures under freeze-thaw cycles [10]. Sun et al. raised a stability calculation method of the permafrost slopes supported by frame structures with anchors [11]. Xu et al. carried out an analysis of the slope stability of the freeze-thaw spalling in the loess areas, and they concluded that the slope safety factor decreased exponentially with the increase of the number of freeze-thaw cycles $[12,13]$, and the slope safety factor negatively correlated with the gradient [14-16]. The stability coefficient of the silty embankment slope can be reduced obviously by freezethaw cycles, and the maximum decrease after freeze-thaw cycles is $49 \%[17,18]$.

The research on slope stability under freeze-thaw cycles mainly focused on homogeneous soil slopes or rock slopes or slopes in the western mountains and the Qinghai-Tibet Plateau. And the study on the stability of the high-ice content soil-rock slope on the National Highway 332 in the permafrost region of Oroqen Autonomous Banner has not been reported. Therefore, our research is necessary.

The purposes of this study are to (1) capture the dynamic changes of the slope during the freeze-thaw cycles, (2) calculate the shallow slip of the slope, and (3) calculate the safety factor of the slope, predict the slope stability, and propose corresponding protective measures.

\section{Materials and Methods}

2.1. Study Site. The slope to be studied is located in the section from Ali River Town to Kubuchun Forest Farm on the National Highway 332, with a total length of $116 \mathrm{~km}$ and a section of permafrost $7.45 \mathrm{~km}$. In this section of permafrost, a certain high-ice content soil-rock mixture slope from $\mathrm{K} 105+700$ to $\mathrm{K} 105+800$ is the object of our field monitoring. This area belongs to the permafrost region of high latitude and low altitude in the Daxing'anling Mountains and is mainly dominated by island-shaped permafrost, which increases the difficulty of slope treatment. Construction of this section started in April 2019.

The slopes we monitored have the following characteristics: thin permafrost cover layer, ice content greater than or equal to $50 \%$, strong thawing, soil-rock combination with stone content occupying greater than $50 \%$, extremely broken volcanic breccia, and quickly formed cold front. Under the ground develops a transparent ice layer and ice-saturated frozen soil, and there are still a lot of bedrock fissure ice and sheer ice layers in the strong-medium weathered rock layer. The internal cracks in the cutting slope of this part are incredibly developed. The excavated ice crystals have less than $20 \%$ solid particles after melting, and the salivary flow ice on the hillside makes construction difficult. During the construction, we found three continuous ice veins in the slope, and many landslides occurred in summer.

In Figure 1, the red point represents the ice-rich cutting slope $(\mathrm{K} 105+700-\mathrm{K} 105+800)$ to be analyzed.
2.2. In Situ Observations. The slope under study has a latitude of $50^{\circ} 35^{\prime} 30.48^{\prime \prime} \mathrm{N}$, a longitude of $123^{\circ} 43^{\prime} 34.33^{\prime \prime} \mathrm{E}$, and an altitude of $772.65 \mathrm{~m}$. In this area, the cold and moderate temperate continental monsoon climate prevails, and the climate change is significant, with substantial annual temperature differences and sizeable daily temperature differences. That is, it has rapid changes between cold and warm, and it also has short summer, fast chilling autumn, and cold and long winter. Field monitoring data show that the average annual air temperature is between $-2^{\circ} \mathrm{C}$ and $-1^{\circ} \mathrm{C}$, and July has the highest temperature, with an average of $17.9^{\circ} \mathrm{C}$ to $19.8^{\circ} \mathrm{C}$. The highest temperature of the year reaches $37.5^{\circ} \mathrm{C}$, and the average annual precipitation is between $450 \mathrm{~mm}$ and $500 \mathrm{~mm}$. Most of the rain is in summer. The freezing period is from October to May of the following year, and the maximum depth of frozen soil is up to $3.5 \mathrm{~m}$. The annual sunshine hours are 2500 hours to 3100 hours, and the sunshine rate is $65 \%$ to $71 \%$. Engineering geological investigation shows that the depth of the permafrost table and base are approximately $-0.7 \mathrm{~m}$ and $-9.6 \mathrm{~m}$, respectively. Besides, the mean annual ground temperature is $-0.42^{\circ} \mathrm{C}$ in this area.

The first- and third-grade slopes shown in Figures 2 and 3 are both $10 \mathrm{~m}$ high sunny soil-rock slopes, with angles of $45^{\circ}$ and $35^{\circ}$, respectively. Volcanic breccia presents throughout the depth of the slopes. In the first-grade slope, when the depth is less than $6.8 \mathrm{~m}$, all are strongly weathered brown-red-gray volcanic breccia. Besides, the structure appears fine-grained or massive, with fissures very developed, and the core is lumpy. In the slope, the depth between $1.2 \mathrm{~m}$ and $2.7 \mathrm{~m}$ is the soil-containing ice layer with ice content greater than $50 \%$; the depth between $2.7 \mathrm{~m}$ and $5.9 \mathrm{~m}$ is the ice-rich frozen soil layer, with visible ice lenses and ice content of $20 \%-30 \%$; the depth between $5.9 \mathrm{~m}$ and $6.8 \mathrm{~m}$ is the fertile frozen soil, with few visible ice crystals, little water seepage, and almost permanent structure after melting. According to the in situ test of Shi et al., Wang et al., and Feng et al.; the formulas of Ren et al. (2020) and Pan et al. (2020); the models of Xu et al. (2020) and Wang et al. (2020), the essential allowable value of the foundation bearing capacity $\left[f_{\mathrm{a} 0}\right]$ and the standard amount of soil friction resistance on the pile side $Q_{\mathrm{ik}}$ are $900 \mathrm{kPa}$ and $160 \mathrm{kPa}$, separately [19-27]. In the third-grade slope, when the depth is less than $7.5 \mathrm{~m}$, all are strongly weathered brown-redbrown-gray volcanic breccia, and the structure is similar to that of the first-grade slope. Besides, the depth between $0.6 \mathrm{~m}$ and $2.2 \mathrm{~m}$ is a soil-containing ice layer with an ice content greater than $70 \%$, which encloses a small amount of rock fragments; the depth between $2.8 \mathrm{~m}$ and $4.9 \mathrm{~m}$ is an ice-rich frozen soil layer; ice lenses and thin ice layers can be seen with an ice content of $20 \%$ to $30 \%$.

Moreover, the slope soil-rock mixtures were collected and transported back to the laboratory for an indoor sieving analysis test. The test results showed that the mass and volume ratio of soil to stone in the slope were 55.04\%: $44.96 \%$ and $69.38 \%: 30.62 \%$, respectively, which are required parameters in ABAQUS numerical simulation.

2.3. On-Site Construction Processes and Methods. We established two monitoring cross-sections "1-1 and 2-2" 


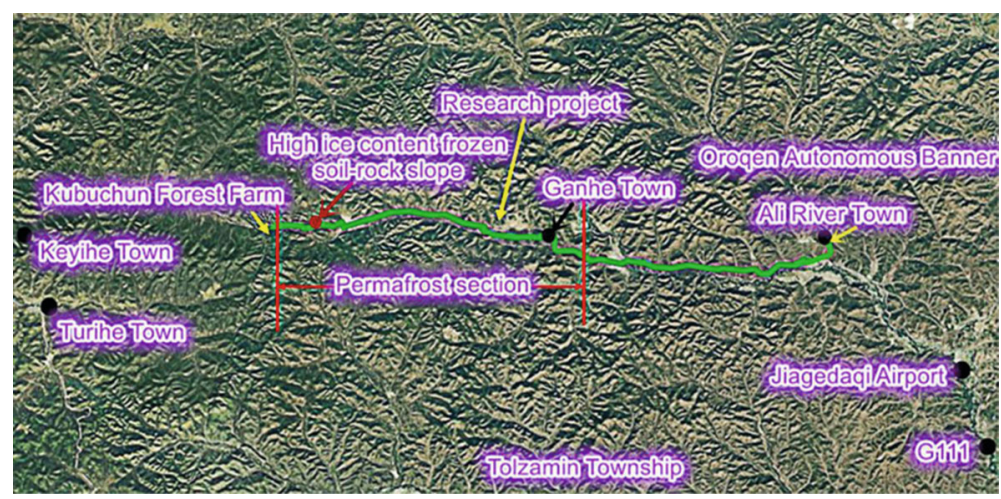

FIgURE 1: Location of the study site.

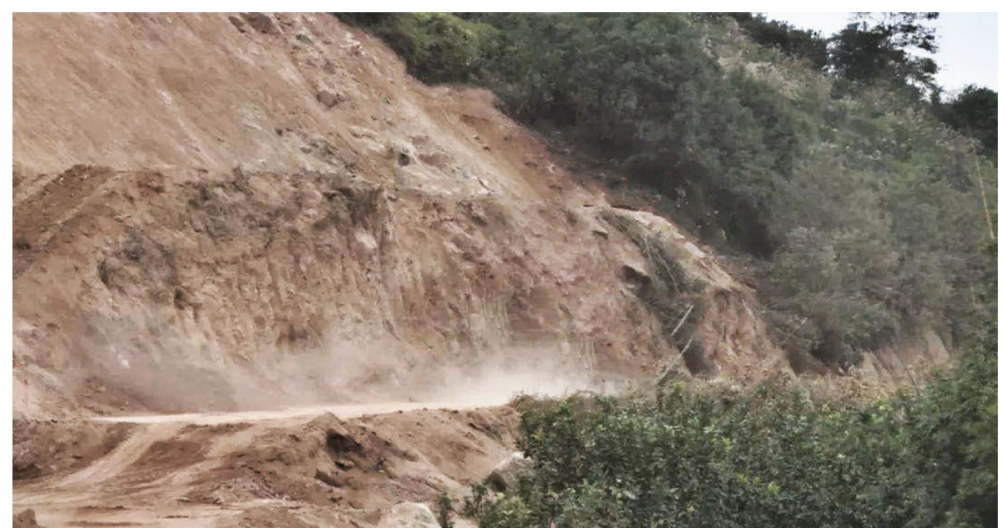

Figure 2: Real view of the slope.

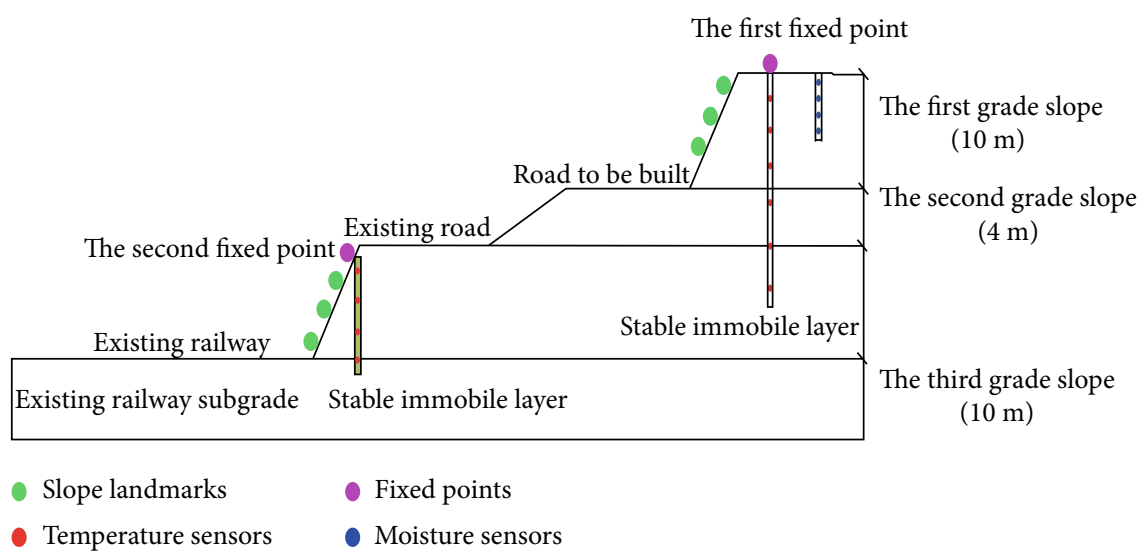

FIgURe 3: Layout of the slope profile.

perpendicular to the road at $\mathrm{K} 105+700$ and $\mathrm{K} 105+750$ in the research, as shown in Figures 4(a) and 4(b).

With reference to the construction practices of Chen et al., we set temperature sensors, moisture sensors, and slope landmarks on the first- and third-grade slopes [28]. To get temperature data in sections "1-1 and 2-2" of the slope, we drilled two temperature boreholes (denoted as T1 and T2) to place the $20 \mathrm{~m}$ long and $10 \mathrm{~m}$ long temperature sensors.

$\mathrm{T} 1$ lied at a horizontal distance of $3 \mathrm{~m}$ inside the top of the first-grade slope at $\mathrm{K} 105+700$, with a $20 \mathrm{~m}$ drilling depth, and we set the temperature sensors every $1 \mathrm{~m}$. T2 is located on the third-grade slope at K105+750, with a horizontal distance of $2 \mathrm{~m}$ from the top of the slope, the drilling depth was $10 \mathrm{~m}$, and a temperature sensor was set every $0.5 \mathrm{~m}$ or $1 \mathrm{~m}$ before or after the $5 \mathrm{~m}$ extent, respectively, with a total of 15 . We tied all temperature sensors together according to the depth. What is more, to prevent the temperature sensor probes from being stuck in the surrounding cable when putting into the borehole, the tape was fixed near each probe, as shown in Figure 5. Before burying the moisture sensors, a test pit $(2 \mathrm{~m} \times 2 \mathrm{~m} \times 2 \mathrm{~m})$ in section 1-1 was dug, and the horizontal distance between $\mathrm{W} 1$ and $\mathrm{T} 1$ was $2 \mathrm{~m}$. The moisture sensor 


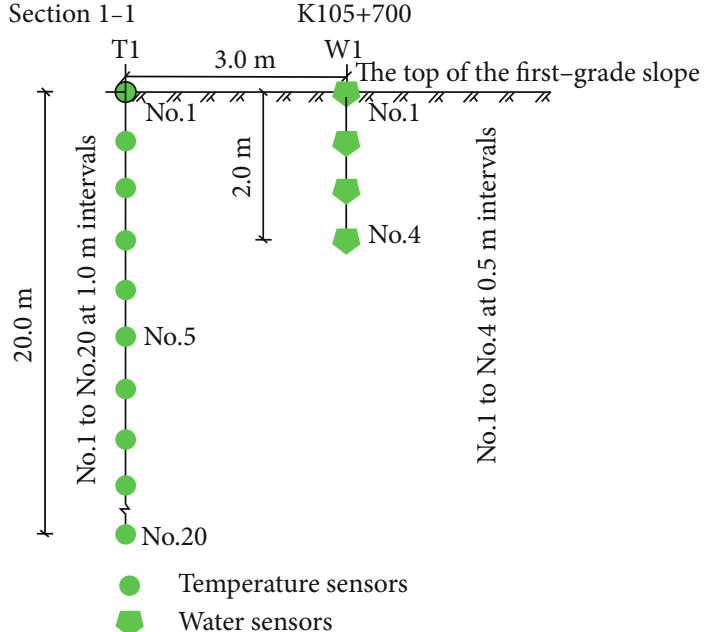

(a)
Section 2-2 K105+750

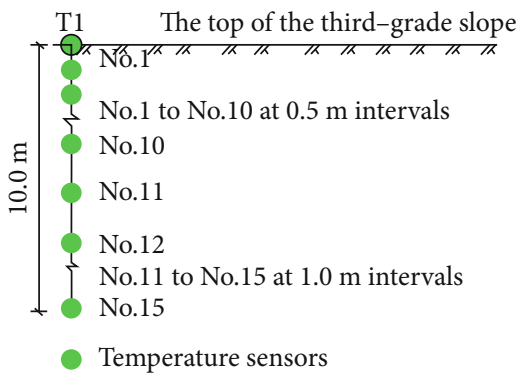

(b)

FIGURE 4: Layout of temperature and moisture sensors in cross-section 1-1 (a) and cross-section 2-2 (b).

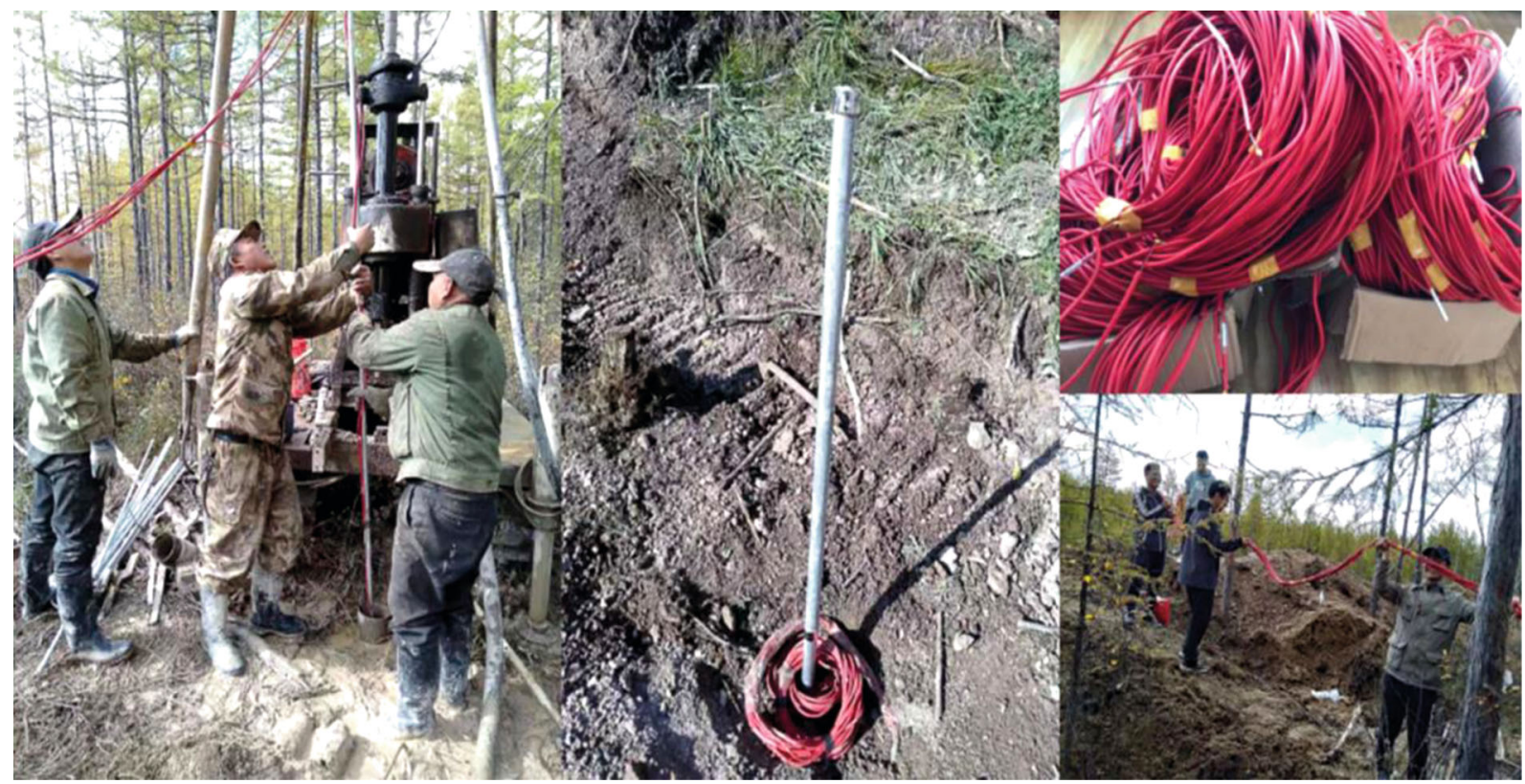

Figure 5: Construction glimpse of the temperature sensor.

was embedded every $0.5 \mathrm{~m}$ along with the $2 \mathrm{~m}$ extent, with a total of 4, as shown in Figure 6. The probe of each moisture sensor is inserted vertically into the pit wall. We arranged nine landmarks uniformly on the first- and third-grade slopes in the section, with a total of eighteen. All the lenses were bound at the upper ends of the landmarks for convenient observation with a total station. When measuring data, these two drilling points were selected as reference points.

In order to obtain a full range of slope deformation under freeze-thaw cycles, we evenly arranged landmarks perpendicular to the slope on the upper, middle, and lower positions of the slope arranging in three rows and three columns, respectively. Each landmark was composed of a 304 stainless steel plate at the bottom, a steel rod fully welded on the stainless steel plate, a lens fixed on the steel rod, and a drill rod which played the role of setting the four corners of the steel plate. Both the length and width of the steel plate were $200 \mathrm{~mm}$, and the thickness was only $3 \mathrm{~mm}$. There were 41 small holes in the steel plate, arranging in a plum blossom shape. The diameter of the small holes was $10 \mathrm{~mm}$. At the center of the steel plate was a steel rod with a length of $300 \mathrm{~mm}$ and a diameter of $10 \mathrm{~mm}$. We welded the bottom of the steel rod and the steel plate fully for binding the lens. The lens was used together with a steel rod. We inserted the steel rod into a circular hole with a diameter of $10.5 \mathrm{~mm}$ reserved on the lens. To prevent the lens from swinging randomly with the external factors such as wind speed, rain, snow, and wild animals, which would affect the measurement accuracy, we tied the lens and steel rod tightly using iron wires. The drill rod was $200 \mathrm{~mm}$ long and $10 \mathrm{~mm}$ in diameter. The lower part 


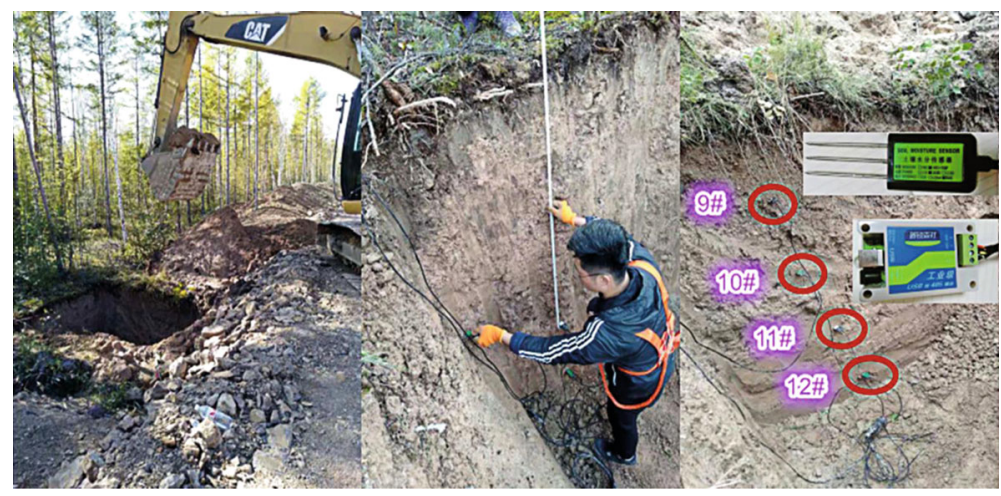

Figure 6: Construction glimpse of moisture sensors.

of the steel rod was conical at three centimeters. We firmly fixed the four corners of each steel plate to the surface of the slope with a drill rod, as shown in Figure 7,

\section{Results}

3.1. Temperature Change Trend Graph of Sections 1-1 and 22. After a one-month commissioning period, we obtained the temperature data in September 2019. At this time, the weather just began to cool down, and it was far from reaching the freezing temperature. Therefore, the frozen soil or rock at this time was in the most primitive state. So, the measured data are the most accurate and favorable for construction. Figure 8 shows the slope temperature in section 1-1.

According to Figure 8, we can capture the following information:

(1) The mean daily slope temperatures were all greater than or equal to $-1.0^{\circ} \mathrm{C}$ before the heavy snow, with the minimum $-1.0^{\circ} \mathrm{C}$ and the maximum $2.7^{\circ} \mathrm{C}$

(2) At the same burial depth, the winter temperature gradually decreased, so the temperature data measured by the temperature sensor also gradually decreased as the date continued. By the end of the observation period, the temperature reduction values of the temperature sensors $1 \#-9 \#$ at each buried depth were $2.5^{\circ} \mathrm{C}, 0.5^{\circ} \mathrm{C}, 0.2^{\circ} \mathrm{C}, 0.3^{\circ} \mathrm{C}, 0.3^{\circ} \mathrm{C}, 0.3^{\circ} \mathrm{C}$, $0.3^{\circ} \mathrm{C}, 0.6^{\circ} \mathrm{C}, 0.4^{\circ} \mathrm{C}, 0.3^{\circ} \mathrm{C}, 0.4^{\circ} \mathrm{C}, 0.5^{\circ} \mathrm{C}, 0.3^{\circ} \mathrm{C}, 0.3^{\circ} \mathrm{C}$, $0.3^{\circ} \mathrm{C}, 0.3^{\circ} \mathrm{C}, 0.3^{\circ} \mathrm{C}, 0.3^{\circ} \mathrm{C}, 0.4^{\circ} \mathrm{C}$, and $0.6^{\circ} \mathrm{C}$, respectively, and the maximum reduction rate was $92.0 \%$

(3) When the burial depth was $0 \mathrm{~m}-3 \mathrm{~m}$, the temperature sensor data gradually decreased because the permafrost table was $-0.7 \mathrm{~m}$. The central part that affected the stability of the sunny slope was near the permafrost table and its top seasonal melting layer. The layer was active and influenced by external temperature, topography, landform, lithology, hydrogeology, vegetation, surface water, and other conditions. In September and October, the atmospheric temperature of Olunchun Autonomous Banner in Hulunbeier City was relatively high, and the slope composition was volcanic breccia. The surface layer was generally sloping gravel and filled with fine-grained soil. The bottom layer was fully strongly weathered volcanic breccia with a small amount of bedrock fissure ice. Stone was a poor conductor of heat and had a relatively low thermal conductivity. According to the geological survey report, $1.2 \mathrm{~m}$ $2.7 \mathrm{~m}$ was a soil-containing ice layer with an ice content greater than $50 \%$, and three noticeable ice vein traces were visible. Therefore, the temperature in this depth range showed a decreasing trend

(4) When the burial depth was $3 \mathrm{~m}-19 \mathrm{~m}$, the temperature sensor data gradually increased as the burial depth increased, which also shows that with the increase of the burial depth, the temperature in the ground increased little by little, which was in line with the change of ground temperature

(5) When the burial depth was $19 \mathrm{~m}-20 \mathrm{~m}$, the temperature did not follow the trend of increasing with depth, because when drilling into a stable stratum at $20 \mathrm{~m}$, we placed twenty steel protective wall tubes binding with temperature sensors into the holes, which disturbed the stratum and increased the heat exchange with the outside world, causing the temperature to drop

(6) After construction, the seasonal active layer was within a depth of $2 \mathrm{~m}$, and the permafrost table had fallen by $1.3 \mathrm{~m}$ compared with the previous value $0.7 \mathrm{~m}$. After drilling to a predetermined depth, it was necessary to fill fine sand into the protective wall tube and seal it for grouting before we buried temperature sensors. As a result of mechanized construction and the removal of surface vegetation, the fragile frozen soil environment was destroyed; the surface state and the frozen water balance state inside the soil were both changed. Therefore, hot melt lakes and depressions were generated; then, the surface water accumulated. What is more, the surface water had a high heat capacity. Its infiltration will input a large amount of thermal energy to the permafrost, which caused the melting of the permafrost to increase; that is, the seasonal melting depth increased, or the permafrost table decreased

Then, we analyzed the temperature data of section 2-2 in the third-grade slope, as shown in Figure 9. The third-grade 


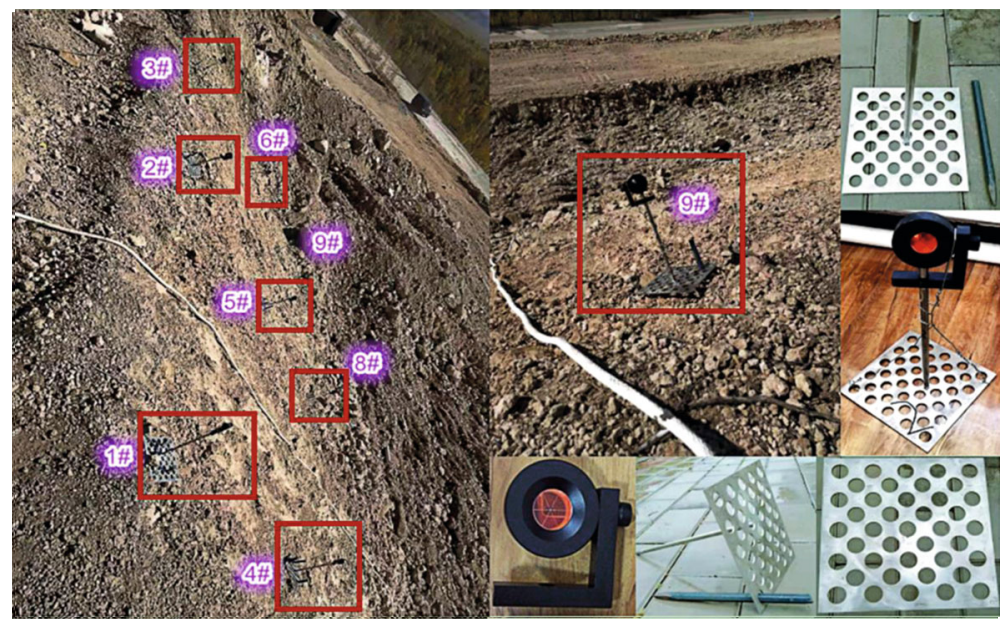

FIGURE 7: Layout of landmarks on the slope.

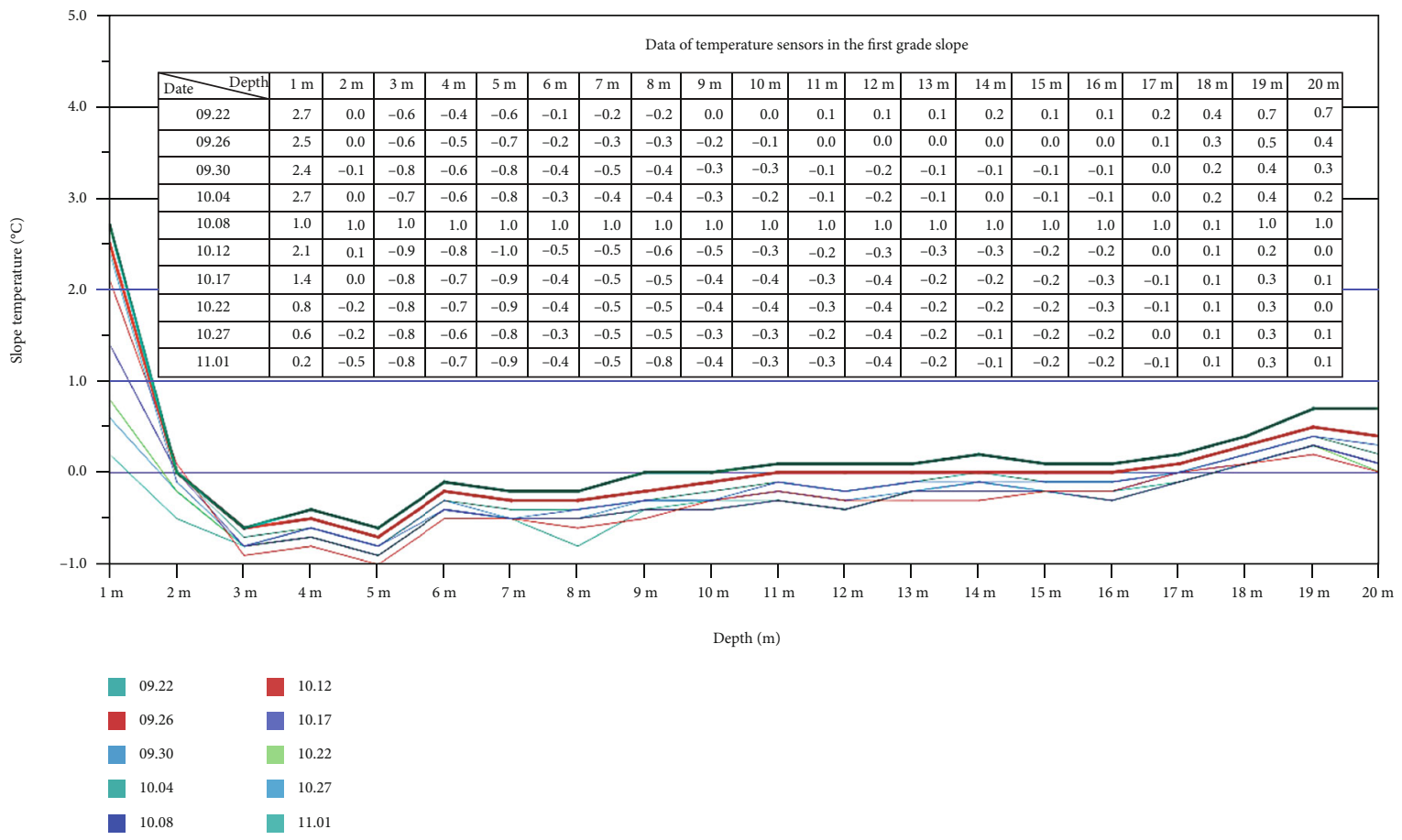

Figure 8: Temperature data diagram of section 1-1 in the first-grade slope.

slope is located below the existing highway, which had a severe uneven settlement and belonged to the embankment slope. The existing road had been in operation, so the third-grade slope had maintained the original balance state many years ago. On the third-grade slope, there were thick forests and dense vegetation. However, the first-grade slope had a high sunny slope, the wind speed was high, the surface was bare, and the sunlight was strong, so the temperature data was very different from the first-grade slope.

According to Figure 9, the temperature change law in the third-grade slope can be obtained:

(1) The mean daily slope temperatures were all greater than or equal to $-0.9^{\circ} \mathrm{C}$ before the heavy snow, with the minimum $-0.9^{\circ} \mathrm{C}$ and the maximum $5.9^{\circ} \mathrm{C}$. At the same burial depth, the winter temperature gradually reduced, so the temperature data measured by the temperature sensors also gradually decreased as the date continued. By the end of the observation period, the temperature reduction values of temperature sensors $1 \#-9 \#$ at each buried depth were $5.5^{\circ} \mathrm{C}$, $2.5^{\circ} \mathrm{C}, \quad 1.0^{\circ} \mathrm{C}, \quad 0.0^{\circ} \mathrm{C}, \quad 0.0^{\circ} \mathrm{C},-0.2^{\circ} \mathrm{C},-0.4^{\circ} \mathrm{C},-0.3^{\circ} \mathrm{C}$, $-0.4^{\circ} \mathrm{C},-0.3^{\circ} \mathrm{C},-0.5^{\circ} \mathrm{C},-0.5^{\circ} \mathrm{C},-0.6^{\circ} \mathrm{C}$, and $-0.6^{\circ} \mathrm{C}$, respectively. And the largest rate of change is $111 \%$

(2) During the observation period, the average temperature of the region was $15.15^{\circ} \mathrm{C}$, and the minimum temperature was $-0.7^{\circ} \mathrm{C}$. When the burial depth was below $1 \mathrm{~m}$, the average temperature of the highest and lowest temperatures was $6.67^{\circ} \mathrm{C}$ and $-6.76^{\circ} \mathrm{C}$, 


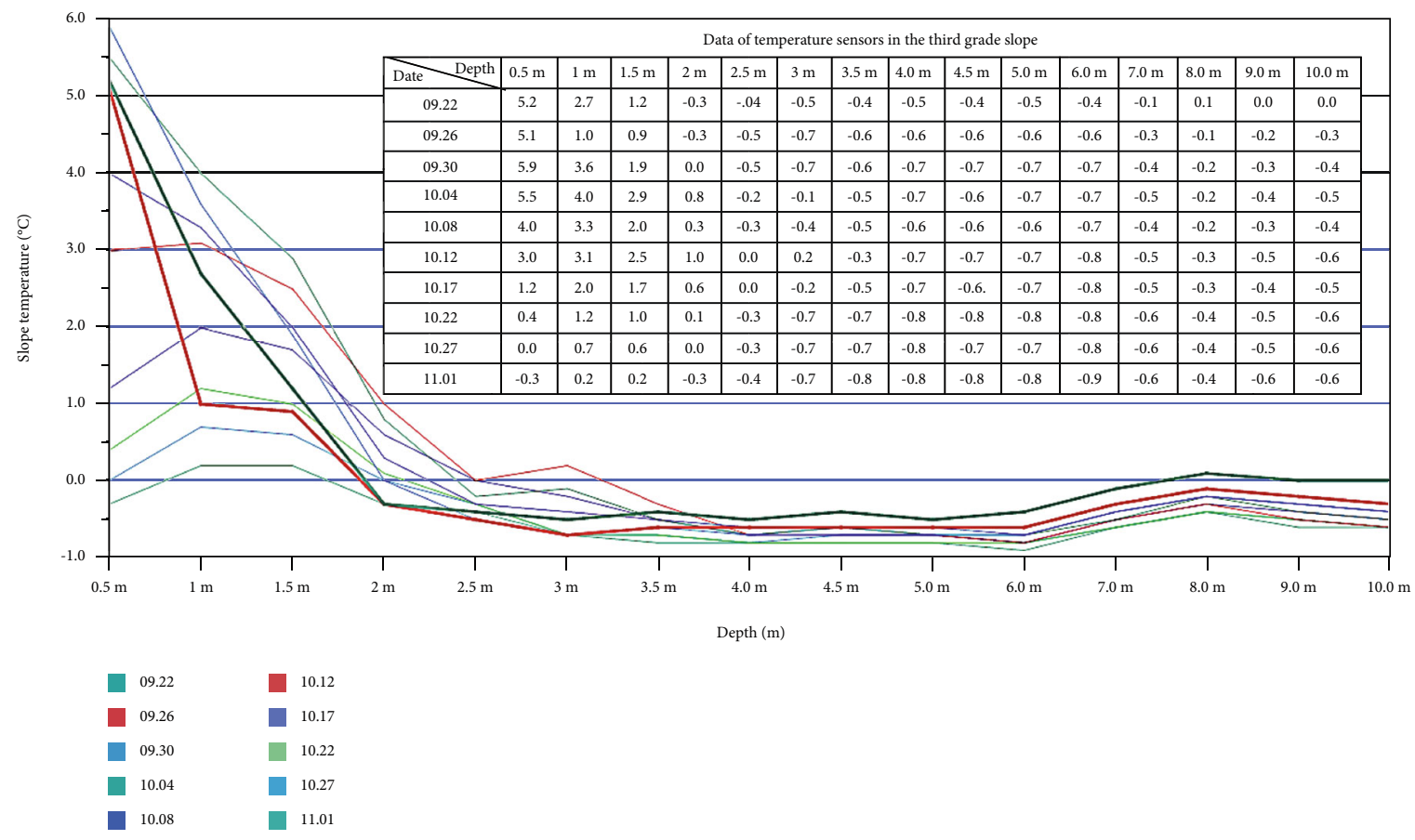

FIgURE 9: Temperature data diagram of section 2-2 in the third-grade slope.

respectively. The atmospheric temperature was relatively low to this extent, and the original equilibrium state changed because of significant disturbance, so the temperature sensor data increased. However, when the burial depth exceeded $1 \mathrm{~m}$, the temperature gradually decreased owing to the influence of the icerich frozen soil layer

(3) When the burial depth was below $6 \mathrm{~m}$, the temperature sensor data gradually decreased with the increase of the burial depth due to the ice-rich frozen soil layer in this range according to the geological survey report, with visible ice lenses and ice content of $20 \%-30 \%$. The situation was similar to the case of 8 m-10 m depth with ice content of 15\%-30\%

3.2. Moisture Change Trend Graph of Section 1-1 in the Slope. According to Figure 10, we can get the change rule of moisture in the slope:

(1) Over time, the weather gradually dried with more water loss. The temperature and free water content decreased little by little, especially when the wind was keen on the first-grade slope, so the moisture sensor data accordingly reduced at the same burial depth between 2019.09.22 and 2019.10.04. The depth range where the water content fell the most was $0.5 \mathrm{~m}-1.5 \mathrm{~m}$, where it was more affected by outside weather, geology, and hydrology than other places. At the end of the observation period, the water content of the moisture sensor 9\#-12\# separately decreased by $1.5 \%, 5.1 \%, 2.3 \%$, and $3.1 \%$, and the change rates were $21.13 \%, 38.93 \%, 14.94 \%$, and $20.13 \%$ at each buried depth
(2) At the same observation time, the observed data were different due to the different burial depths, and the closer to the bottom of the pit, the larger the water content due to being less affected by external vegetation, wind, temperature, and other external influences, then the better the water retention of the soil. At the same time, due to the aggregation effect and gravity, the water content became larger. The moisture sensors 9\#-12\# were measured eight times in total; the increase in water content at each observation from the top of the pit to the bottom was $8.3 \%$, $8.7 \%, 8.8 \%, 8.4 \%, 5.8 \%, 5.5 \%, 7.7 \%$, and $6.7 \%$, in which the change rate of each time was $116.90 \%$, $138.10 \%, 149.15 \%, 127.27 \%, 152.63 \%, 119.57 \%$, $148.08 \%$, and $119.64 \%$.

(3) At the same burial depth, the moisture sensor data increased between 2019.10.04 and 2019.10.08. The reason is that the pit was originally open-air, and then the backfilling carried out on 2019.10.04, causing the water retention of the soil in the hole to increase. Therefore, the water content rose. Then, the water content gradually decreased, affected by dry and windy weather at the same burial depth between 2019.10.08 and 2019.10.12. Due to the drops of rain, hail, blizzard, and other weathers, the data of the moisture sensor increased at the same buried depth between 2019.10.12 and 2019.10.27, indicating that the moisture content in the shallow layer of the slope was relatively affected by the outside world. Therefore, we should pay close attention to the change of water content in the superficial layer and slope protection during the entire life cycle of the slope 


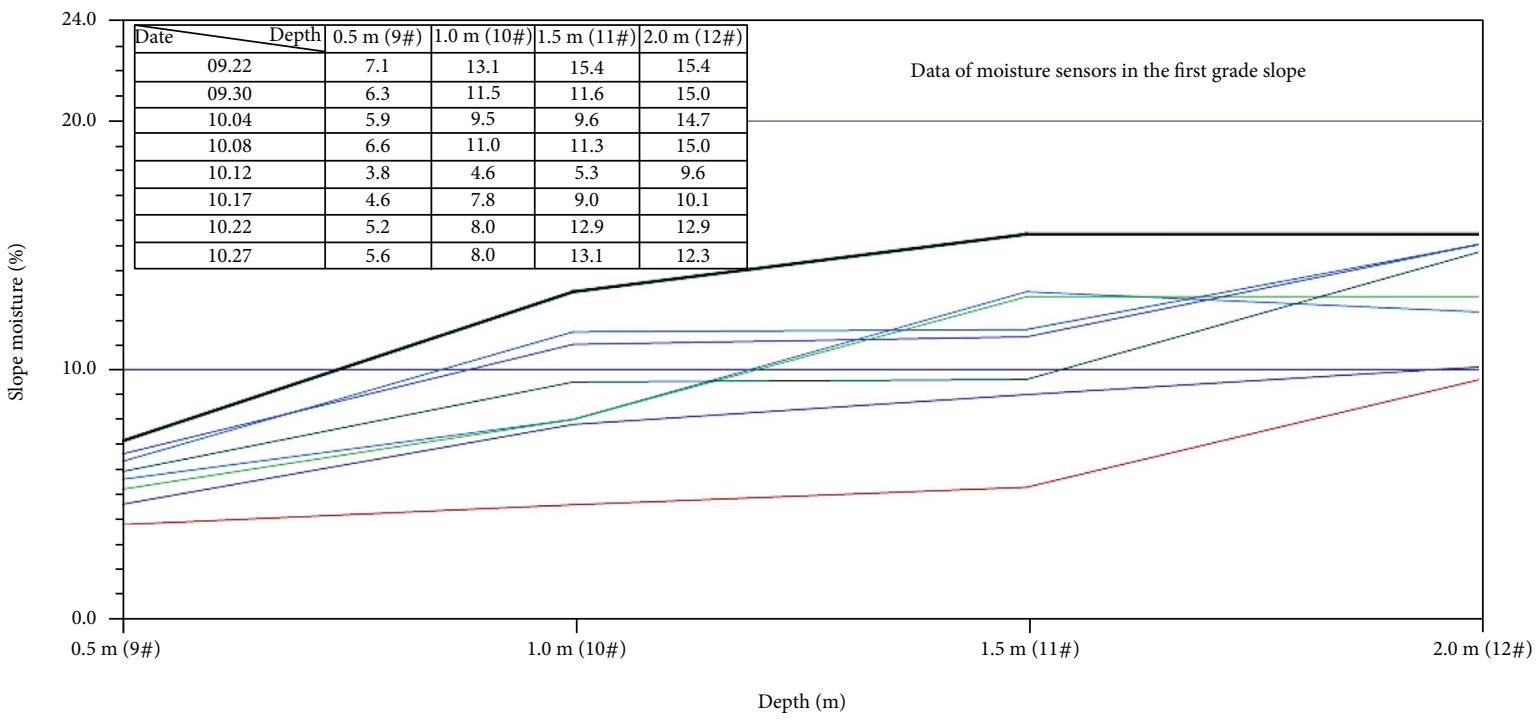

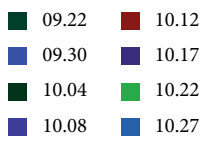

FIGURE 10: Moisture diagram of section 1-1 in the first-grade slope.

\subsection{Deformation and Settlement Observation of the First- Grade Slope}

3.3.1. Changes in the Vertical Angle of Landmarks. The vertical angle, also known as the height angle, refers to the angle between the sightline and horizontal line. It is the vertical angle between the center axis of the instrument and the observation point. The tolerance of the difference in the vertical angle of the total station one measurement back is $12^{\prime \prime}$.

It can be seen from Figure 11 that before November, the vertical angle fluctuates periodically with the freeze-thaw cycle. After November, the slope has been in a state of negative temperature. The volume of the slope increases after the moisture in the slope is frozen, and the slope is uplifted by frost heave, causing the vertical angle to become larger and larger. The vertical angle has been increasing throughout the winter. After entering the spring thawing season, the slope begins to thaw, so the vertical angle begins to decrease until the next cycle of freeze-thaw. Therefore, the vertical angle is an important indicator to measure the degree of freeze-thaw of a slope, and it is often used in the calculation of the shallow slumping amount of a slope.

3.3.2. Changes in the Height Difference of Landmarks. The height difference was the difference in elevation between two points, that is, the end elevation minus the starting elevation. Firstly, select a surface as the reference surface and then measure the height of the two points relative to the reference surface. The difference between the two heights is the height difference.

According to Figure 12, we can get that the curve had a slight upward trend, indicating that when entering winter, frost heaving had been going on, especially during the period of 2019.10.17 to 2019.10.22, because there were sleet and moderate snow during this period. And the weather gradually became colder due to multiple drops of rain and storms; then, frost heave was the most obvious at this time. After entering the summer, the slope was in a melting state, so the last part of the curve in the figure showed an upward trend.

It can be seen from Figure 12 that the slope has been in dynamic changes with the freeze-thaw cycles. After entering September, as time goes by, the temperature gradually decreases, and the frost heave of the slope gradually accumulates, causing the frost heave to be greater than the thaw settlement. Therefore, the slope is raised by frost heave, and the height difference between the reference point and the landmarks on the slope is getting larger and larger, so the height difference curve in Figure 12 has been showing an upward trend before entering the spring thaw period. On the contrary, the weather is warmer and the temperature gradually rises during the spring thaw period. As time goes by, the melting amount of the slope begins to be greater than the frost heave, causing the height difference between the landmarks on the slope and the reference point to become smaller and smaller, so the height difference curve in Figure 12 has been showing a downward trend during the spring melting period. Monitoring data shows that after the construction of the side slope of the cutting, the permafrost in the area has been in a degraded state and is irreversible. Therefore, during construction in permafrost areas, we must adhere to the principle of filling more and digging less.

3.3.3. Numerical Simulation of Slope Stability. According to the geological survey report, in the K105+700-K105+800 part of the high-ice content soil-rock slope, its composition was the same. A $1 \mathrm{~m} \times 1 \mathrm{~m} \times 1 \mathrm{~m}$ range was sampled to minimize 


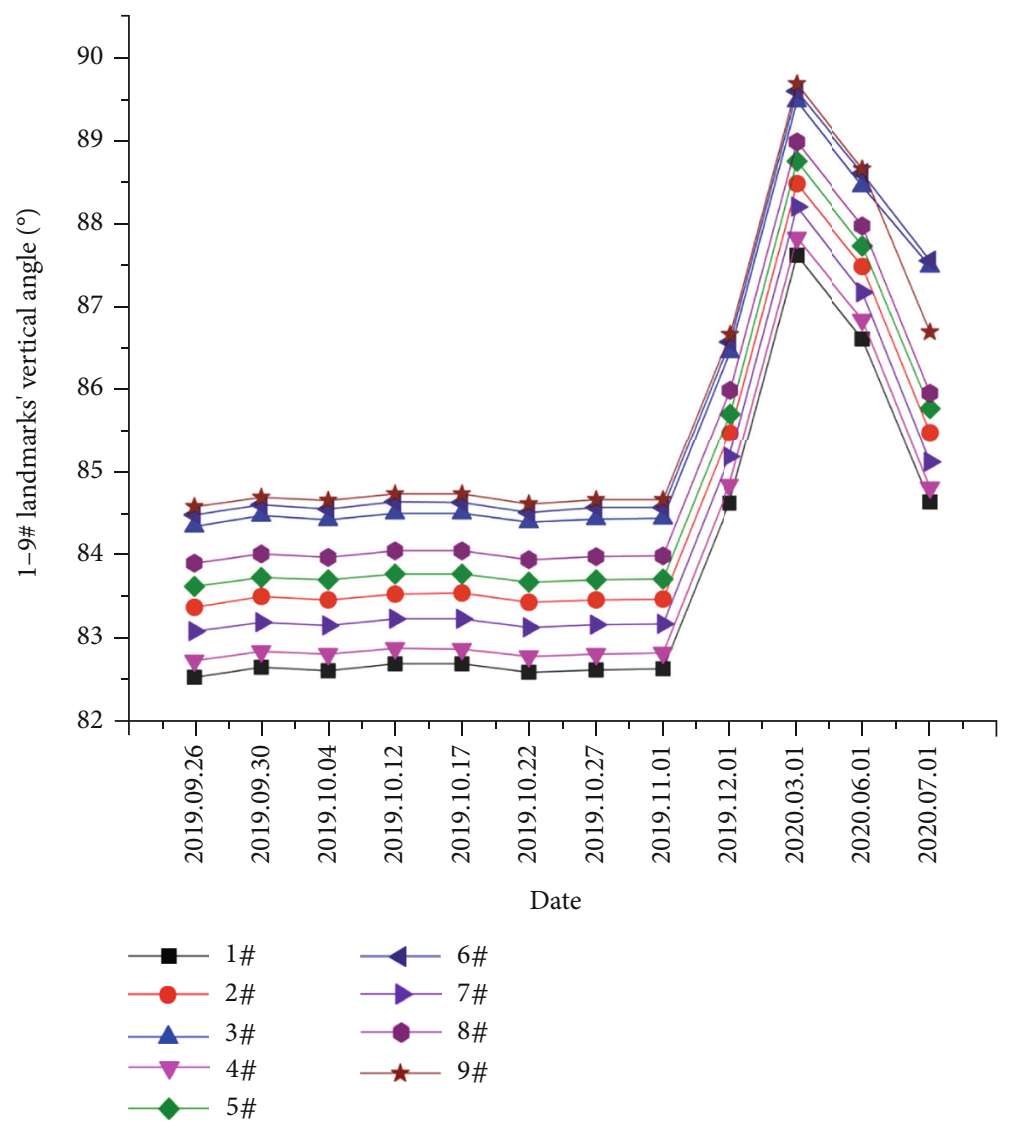

FIGURE 11: Vertical angle change charts of landmarks on the first-grade slope.

the disturbance to the slope, and then we weighed, sealed, and then transported them back to the laboratory for testing.

The sampling process is in Figure 13. After the sieving test, we set the threshold between soil and stone as $5 \mathrm{~mm}$. Particles with a diameter smaller and greater than $5 \mathrm{~mm}$ were defined as soil and stone, respectively. And the volume ratio of soil to stone in the soil-rock slope was $55.04 \%: 44.96 \%$. Among the $44.96 \%$, stones with a particle size of [ $5 \mathrm{~mm}, 10$ $\mathrm{mm}),[10 \mathrm{~mm}, 20 \mathrm{~mm}),[20 \mathrm{~mm},+\infty)$ accounted for $22.6 \%$, $26.0 \%$, and $51.4 \%$, separately. Taking the sample $6 \#$ as an example, the screening test results are in Figure 14. With reference to the modeling experience of Chen et al. [29] and Zhu et al. [1], we wrote the above data into code with the help of Python software, and after running the code in ABAQUS software, we got the model diagram of the soil-rock mixture slope, as shown in Figure 15. The physical parameters, mechanical parameters, and thermal parameters used in the model are shown in Table 1. The specified constraints were as follows: the left and right sides of the slope constrained the horizontal displacement, the bottom of the slope was hinged, and the rest of the slope were free boundaries. The film coefficient in this model was chosen as $25 \mathrm{~W} / \mathrm{m} 2 \times{ }^{\circ} \mathrm{C}$. After two hundred freeze-thaw cycles, the shallow slip of the slope was obtained, as shown in Figure 16.

In Figure 16, when the slope reaches the limit equilibrium state after two hundred freeze-thaw cycles, the slippage of node 1 is $6.811 \mathrm{~cm}$ in ABAQUS; this is consistent with the results of field measurements. At this time, the safety factor of the slope is 0.997 , and the slope has reached the limit equilibrium state. If slope protection measures are not taken, the consequences will be disastrous. Therefore, slope protection measures are very important. Moreover, in order to control the shallow slippage of the slope under freeze-thaw cycles in permafrost regions during the whole life cycle of the slope, slope protection measures must be taken seriously and strictly implemented from the beginning of the design stage to the end of the operation period.

\section{Discussion}

We obtained temperature-moisture-displacement data of the high-ice content soil-rock slope in permafrost regions of the primary highway on National Highway 332 in Oroqen Autonomous Banner, Hulunbeier City, Inner Mongolia Autonomous, in the study. At the same time, we used the numerical simulation software ABAQUS to simulate the slope stability and proposed measures for slope protection. After each freeze-thaw cycle, the soil and rock particles on the slope move down a short distance along the hillside [30-34], and the more the freeze-thaw cycles, the greater the slip. This phenomenon is called the frost creep $[35,36]$. Over time, the stability of the slope decreases, and even landslides occur, especially when the weather is warmer, after rain and snow, as shown in Figures 17(a)-17(c) below.

After calculation, all the landmarks on the first-grade slope slipped along the hill from September to November in 


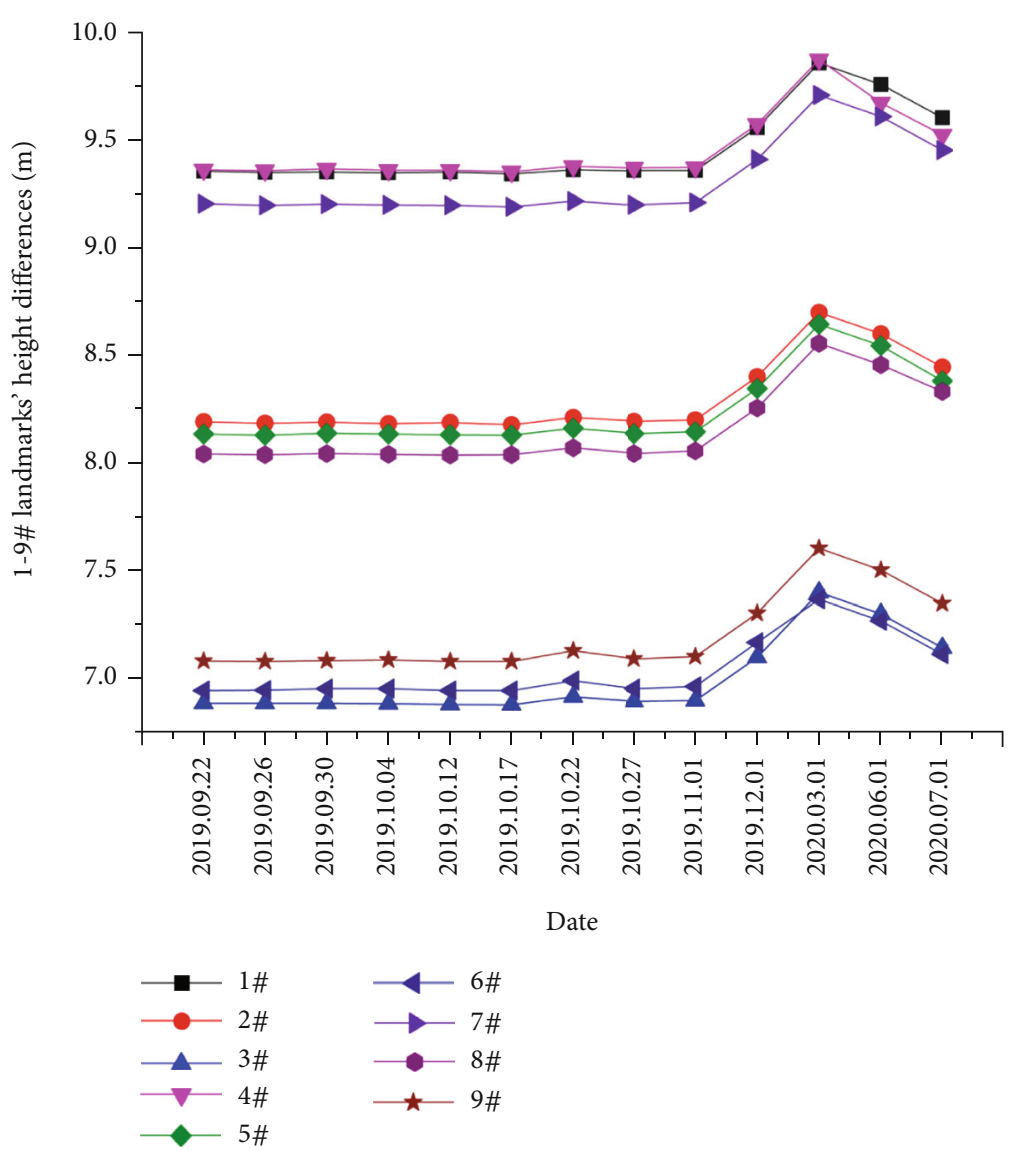

FIGURE 12: Height difference change charts of landmarks on the first-grade slope.

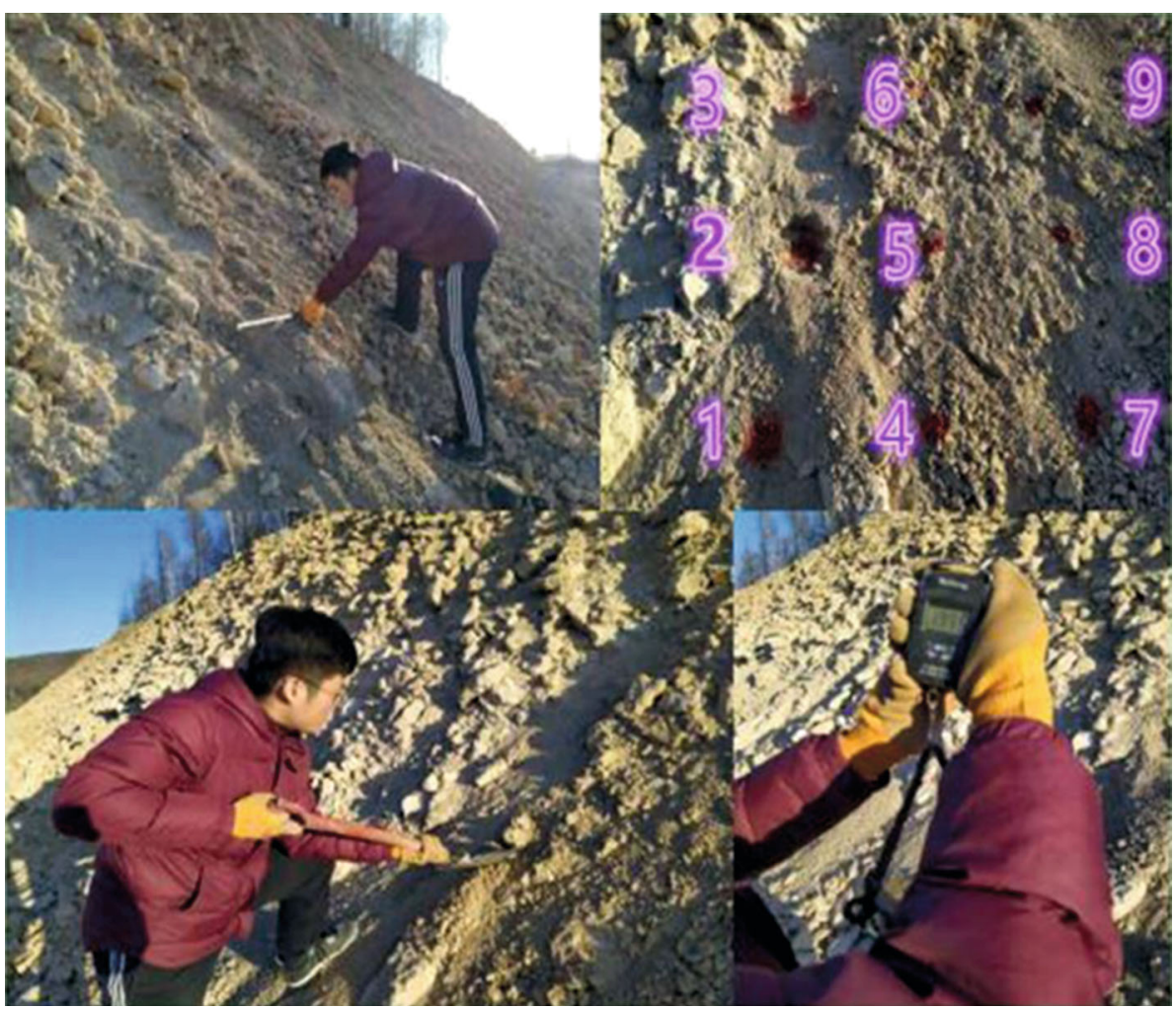

FIGURE 13: The soil-rock mixture sampling process. 


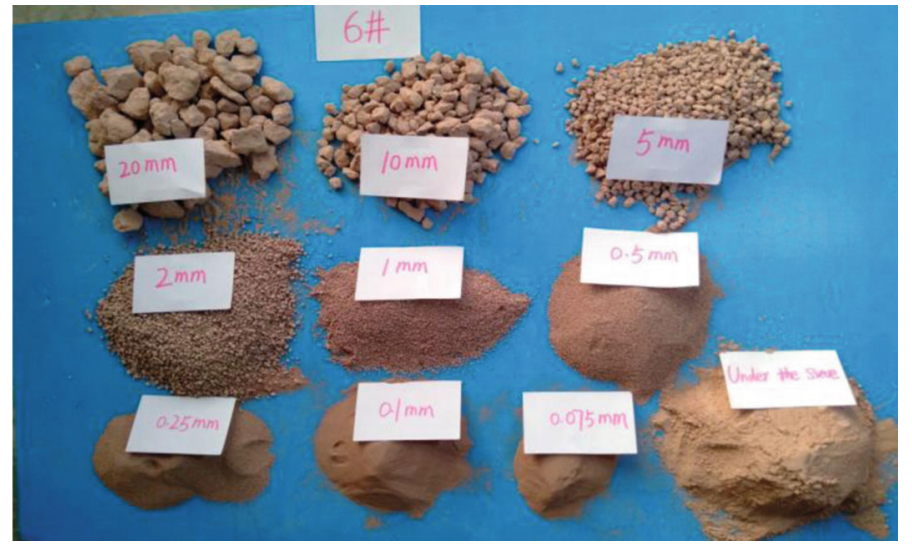

FiguRE 14: The screening test results of soil-rock mixture sample 6\#.

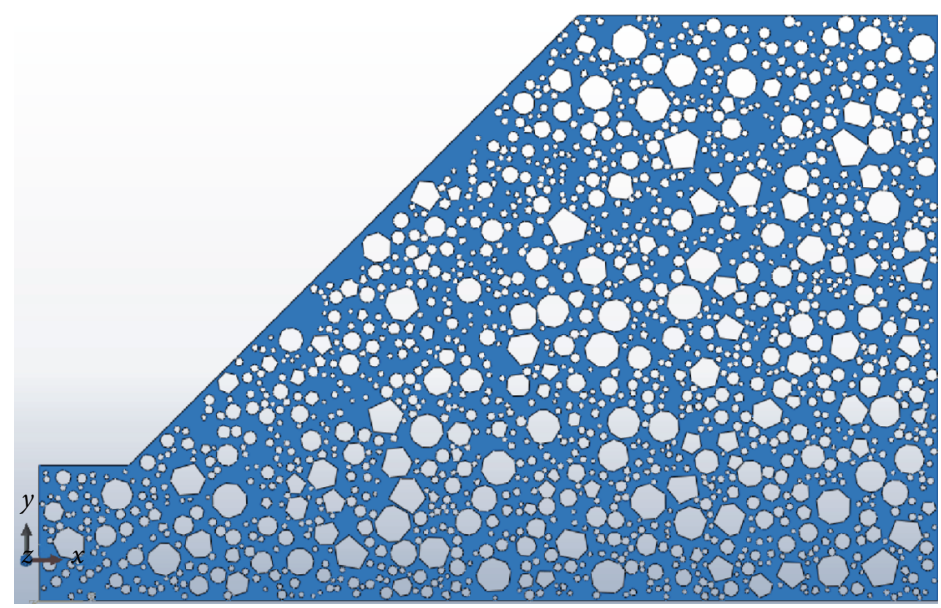

FIGURE 15: Schematic diagram of soil-rock slope composition in ABAQUS.

TABle 1: Physical and mechanical parameters of specimens in the slope.

\begin{tabular}{lcc}
\hline Density $\left(\mathrm{kg} / \mathrm{m}^{3}\right)$ & Water content $(\%)$ & Cohesion $(\mathrm{kPa})$ \\
1970 & 6.95 & 2.89 \\
Internal friction angle $\left({ }^{\circ}\right)$ & Linear expansion coefficient $\left(10^{-6}\right)$ & Thermal conductivity $(\mathrm{W} / \mathrm{m} \times \mathrm{K})$ \\
27.40 & 9.72 & 0.45 \\
Specific heat capacity $\left(\mathrm{J} / \mathrm{g} \cdot{ }^{\circ} \mathrm{C}\right)$ & Elastic modulus $(\mathrm{GPa})$ & Compressive strength $(\mathrm{GPa})$ \\
0.87 & 2.49 & 38.83 \\
\hline
\end{tabular}

2019 , of which landmark $6 \#$ was the most obvious, which slid down about $1 \mathrm{~cm}$, approximately equal to $10 \%$ of the slope height. This decline rate was huge. The same phenomenon occurred in the third-grade slope, and landmark 9\# slid farthest with $8.5 \mathrm{~mm}$ by analysis, approximately $8.5 \%$ of the slope height. And there are many shallow trenches and cracks on the slope surface, which were traces left by the creep. The creep is a significant deformation feature of frozen soil, and freeze-thaw erosion is the leading cause of the creep, as shown in Figure 17(c). After many freeze-thaw cycles, the shallow sliding on the slope surface happens, which can be illustrated in Figure 18.

As shown in Figure 18, assuming that the solid yellow line represents the slope before the frost heave, the red dashed line represents the slope after the frost heave, the letter $H$ represents the amount of frost heave, $G$ represents the direction of gravity, and $D$ represents the amount of movement. When the slope is subject to frost heave, the pore water converts into ice, and the soil and rock particles on the slope uplift when the volume increases by about $9 \%$ along the $H$ direction, which is perpendicular to the slope surface. And when melting, the particles affected by gravity and the slope angle fall straight in the $G$ direction. After each freeze and thaw, the particles of the slope move down a short distance from the original position along the slope. Day after day, especially in the spring thaw season with freezing at night and melting at noon, we can capture the noticeable creep of the particles on the slope [10]. 


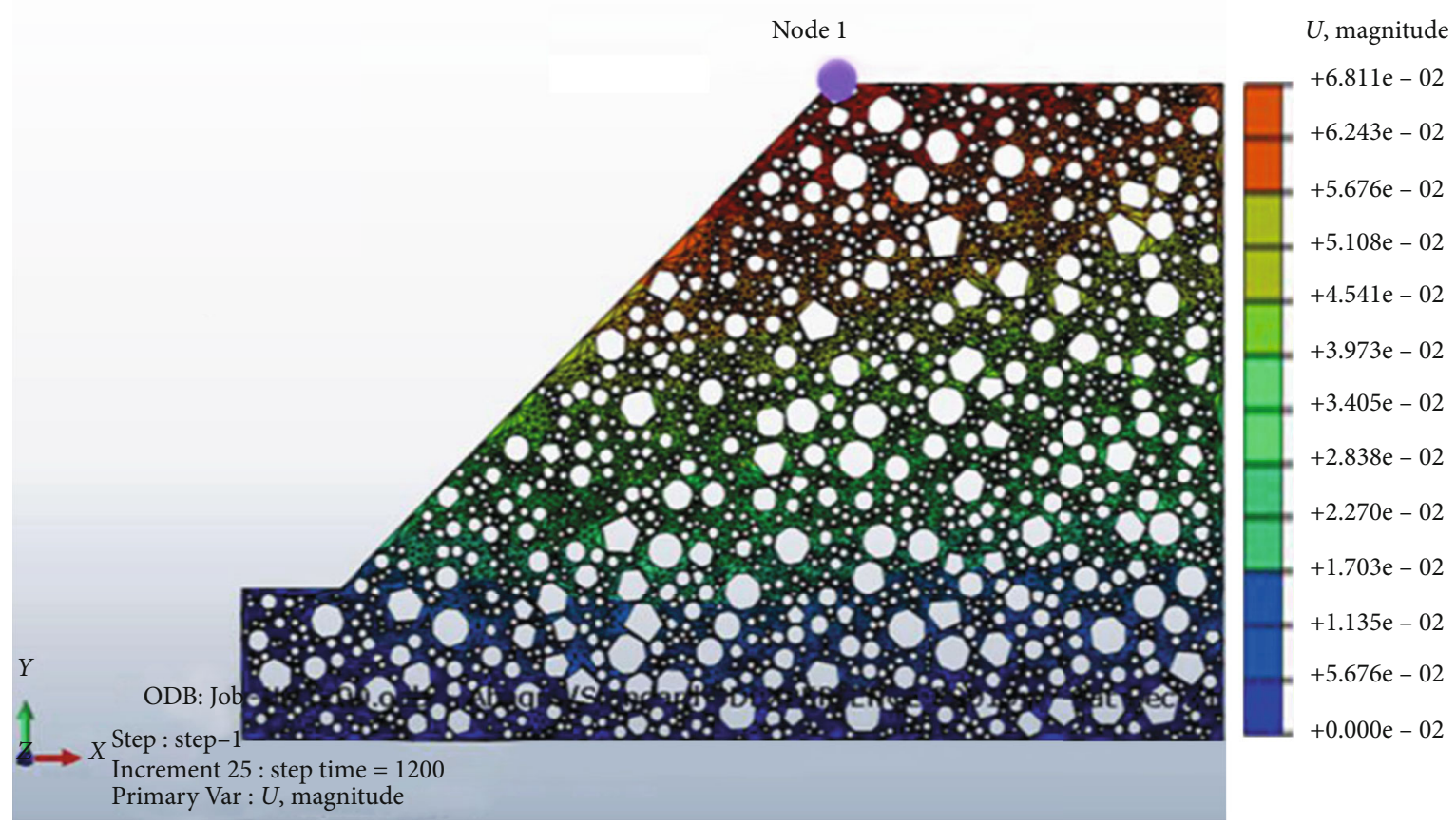

FIgURE 16: Displacement cloud map after two hundred freeze-thaw cycles.

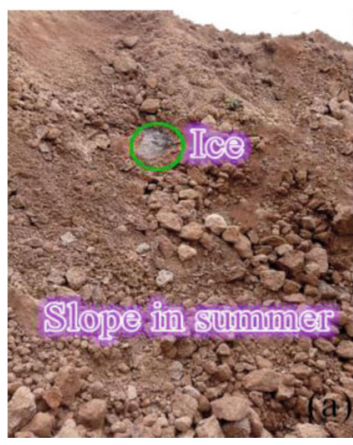

(a)

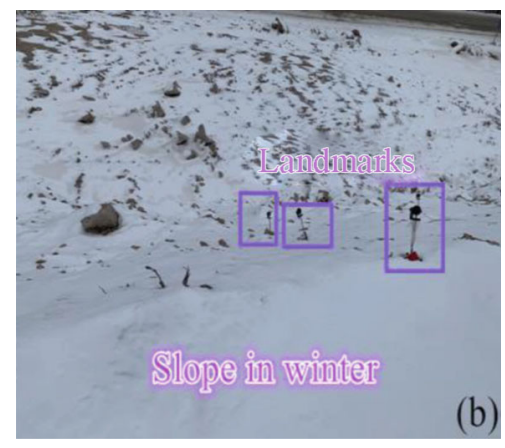

(b)

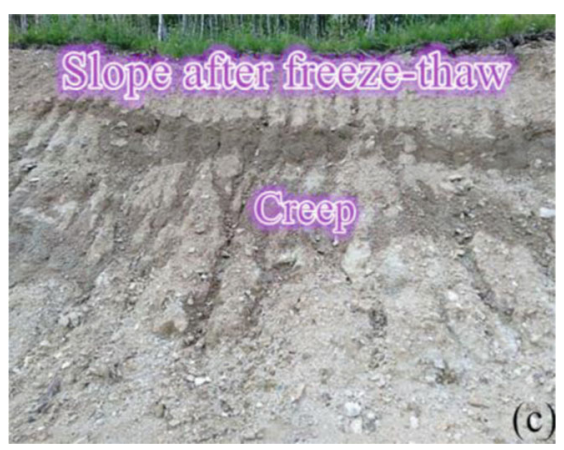

(c)

FIGURE 17: Physical map of the frozen soil-rock slope with high ice content.

The degree of freeze-thaw erosion can be minimized by preventing the snow from melting and seeping into the slope, setting a heat insulation layer or crushed rock layer, controlling the slope angle, increasing the vegetation coverage, and reducing the temperature of the slope $[37,38]$. Landslide is a common disaster of slopes in permafrost regions. Traditional methods are difficult to monitor and warn effectively $[39,40]$. After experimenting, Tao et al., Huang et al., and Ren et al. proved that a new remote monitoring and forecasting system for landslides by adopting the constant resistance 


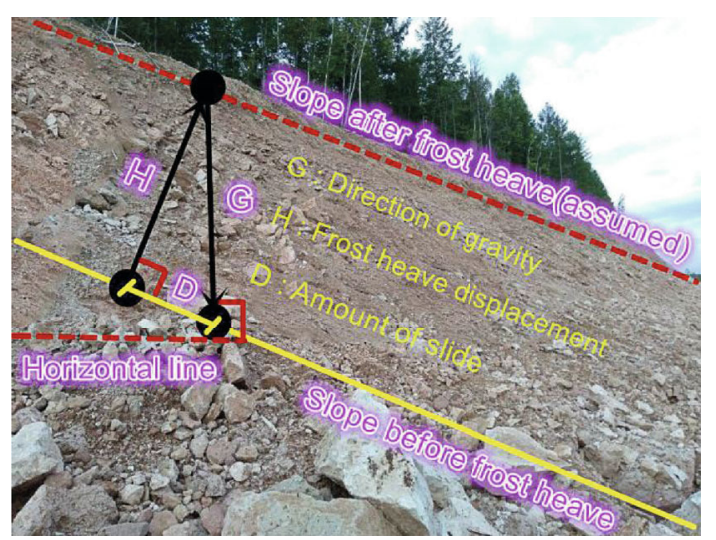

FIGURE 18: Creep schematic diagram of the soil-rock slope under freeze-thaw action.

and large deformation (CRLD) anchor cable to control impact resistance, large deformation, and energy absorption was feasible [41-43].

In engineering practice, we can combine the abovementioned traditional methods of slope protection with new monitoring and early warning systems to better serve slopes in permafrost regions.

\section{Conclusions}

A study on the stability of the high-ice content soil-rock cutting slope on National Highway 332 in the high-latitude permafrost regions of the Daxing anling Mountains in Oroqen Autonomous Banner was conducted on the basis of the field in situ monitoring, indoor experiment, and ABAQUS numerical simulation model. The conclusions are as follows:

(1) The mean daily slope temperatures are all greater than or equal to $-1.0^{\circ} \mathrm{C}$ and $-0.9^{\circ} \mathrm{C}$ of the first- and third-grade slopes, with the maximum $2.7^{\circ} \mathrm{C}$ and $5.9^{\circ} \mathrm{C}$, respectively. At the same burial depth, the temperature sensor data gradually decreases as the date continues, with the maximum reduction value of separately $2.5^{\circ} \mathrm{C}$ and $5.5^{\circ} \mathrm{C}$. And the maximum rate of change is $111 \%$. When the burial depth is $0 \mathrm{~m}-3 \mathrm{~m}$ and $19 \mathrm{~m}-20 \mathrm{~m}$ in the first-grade slope, the temperature sensor data gradually decreases due to the changed original equilibrium state, permafrost table, soilcontaining ice layer, ice veins, and disturbed stratum, while at other depths, the temperature sensor data gradually increases, which is in line with the change of ground temperature. After construction, the seasonal active layer is within $2 \mathrm{~m}$, and the permafrost table has fallen by $1.3 \mathrm{~m}$ compared with the previous value $0.7 \mathrm{~m}$

(2) At the same observation time, the closer to the bottom of the pit, the larger the water content. The maximum value increase in water content of moisture sensors 9\#-12\# at each observation from the top of the pit to the bottom was $8.8 \%$, in which the change rate was $149.15 \%$. Furthermore, the moisture decreases accordingly at the same burial depth on 2019.09.22 to 2019.10.04 and 2019.10.08 to 2019.10.12, owing to drier weather and stronger wind and the maximum water content reduction, and their rates are $5.1 \%$ and $38.93 \%$, respectively. However, the data increased between 2019.10.04 and 2019.10.08 on account of the pit backfill. Besides, because of many drops of rain, hail, and blizzard, the water content increased between 2019.10.12 and 2019.10.27, indicating that the moisture content in the shallow layer of the slope is relatively affected by the outside world. Therefore, we should pay close attention to the change of water content in the shallow layer and adopt measures to protect the slope during the entire life cycle of the slope

(3) The vertical angles of landmarks 1\#-9\# on the firstgrade periodically increase firstly and then decrease, with a floating amplitude of $0.15^{\circ}$, which exceeds the allowable error $12^{\prime \prime}$, indicating that the landmarks were in the cycle of periodic frost heaving and melting, corresponding to the changes in atmospheric temperature. Each height difference curve has an upward trend, indicating that when entering winter, frost heaving has been going on, especially during the period in the rainy and snowy seasons. After numerous freeze-thaw cycles, the landmarks on the slope moved down a distance along the slope, so we can combine the abovementioned traditional methods of slope protection with the new monitoring and early warning system to better serve slopes in permafrost regions

Moreover, in order to further grasp the deformation and settlement rules to analyze the stability of the high-ice content soil-rock slopes in the permafrost region under freezethaw conditions, long-term field monitoring, laboratory tests, and numerical simulations about the slope will be conducted continuously.

\section{Data Availability}

The figures presenting the test data analysis were all drawn in AutoCAD 2019 and Origin 8.0. The field in situ monitoring, indoor freeze-thaw tests, thermal parameter tests, and ABAQUS numerical simulation data files used to support the findings of this study are available from the corresponding author upon request.

\section{Additional Points}

Invention Patent Name. Soil-rock dam crack repair structure and repair method thereof. Application Publication Number. CN110952509A. Applicant. China University of Geosciences (Beijing). Inventor. Yuxia Zhao. Invention Patent Abstract. The invention discloses a crack repair structure of an earthrock dam, which comprises a triangular groove opened at the crack, and a plurality of installation holes are symmetrically opened on the inner walls of both sides of the triangular groove. A fixing sleeve is fixed in the mounting hole, a 
reinforcing rod is installed between the two symmetrical fixing sleeves, a concrete layer is filled in the triangular groove, the top surface of the concrete layer is lower than the bottom surface of the reinforcing rod, and a sand layer is laid on the concrete layer. The fixing sleeve includes a housing, two first springs are installed at the bottom of the housing, two pressure pieces are connected to the first spring, and the axis angle of the two pressure pieces is $30^{\circ}$; the reinforcing rod includes a rod body, both ends of the rod body are threadedly connected with the ends, the ends are shafted with plugs, the plugs are provided with sockets for inserting and mating with the pressure piece, and the outer edges of the ends are fixed and crimped with the shell seal, the sealing ring in contact. The invention can improve the shortcomings of the prior art, improve the overall rigidity of the dam body, and ensure its resistance to deformation and cracking.

\section{Conflicts of Interest}

The authors declare that there are no conflicts of interest regarding the publication of this paper.

\section{Authors' Contributions}

The contributions of the authors involved in this study are as follows: conceptualization, Hongyan Liu, Yuxia Zhao, Jun Feng, Qi Wu, and Kangqi Liu; methodology, Yuxia Zhao and Jun Feng; software, Hongyan Liu, Yuxia Zhao, and Kangqi Liu; validation, Jun Feng and Liqun Wang; investigation, Yuxia Zhao, Jun Feng, and Kangqi Liu; resources, Jun Feng and Liqun Wang; data curation, Yuxia Zhao, Jun Feng, and Kangqi Liu; writing-original draft preparation, Yuxia Zhao and Jun Feng; writing-review and editing, Yuxia Zhao and Kangqi Liu; project administration, Hongyan Liu, Jun Feng, and Liqun Wang; project financial acquisition, Hongyan Liu, Jun Feng, Liqun Wang, Yuxia Zhao, and Kangqi Liu. All authors have read and agreed to the published version of the manuscript.

\section{Acknowledgments}

We gratefully acknowledge the School of Engineering and Technology, China University of Geosciences (Beijing), and Beijing Municipal Road \& Bridge (Group) Co., Ltd., for the financial support, surveyed data, and comments on the project (Key Techniques of Frozen Soil Road Construction in High-Latitude and Low-Altitude Forest Areas) they worked together on. We would also like to thank Guangxi Road and Bridge Engineering Group Co., Ltd., and others in this collaborative project who have helped us in drilling, sampling, equipment, transportation, and accommodation. These supports are greatly appreciated.

\section{References}

[1] C. Zhu, M. C. He, M. Karakus, X. B. Cui, and Z. G. Tao, "Investigating toppling failure mechanism of anti-dip layered slope due to excavation by physical modelling," in Rock Mechanics and Rock Engineering, 2020.
[2] G. Y. Li, W. Ma, F. Wang et al., "Processes and mechanisms of multi-collapse of loess roads in seasonally frozen ground regions: a review," Sciences in Cold and Arid Regions, vol. 7, pp. 456-468, 2015.

[3] Y. L. Qu, G. L. Chen, F. J. Niu, W. K. Ni, Y. H. Mu, and J. Luo, "Effect of freeze-thaw cycles on uniaxial mechanical properties of cohesive coarse-grained soils," Journal of Mountain Science, vol. 16, no. 9, pp. 2159-2170, 2019.

[4] J. Xu, Z. Q. Wang, J. W. Ren, S. H. Wang, and L. Jin, "Mechanism of slope failure in loess terrains during spring thawing," Journal of Mountain Science, vol. 15, no. 4, pp. 845-858, 2018.

[5] D. K. Liu, Z. L. Gu, R. X. Liang et al., "Impacts of pore-throat system on fractal characterization of tight sandstones," Geofluids, vol. 2020, 17 pages, 2020.

[6] D. X. Qu, Y. Luo, X. P. Li, G. Wang, G. Zhang, and K. Xu, "Study on the stability of rock slope under the coupling of stress field, seepage field, temperature field and chemical field," Arabian Journal for Science and Engineering, vol. 45, no. 10, pp. 8315-8329, 2020.

[7] X. Wang, C. Liu, S. Chen, L. Chen, K. Li, and N. Liu, "Impact of coal sector's de-capacity policy on coal price," Applied Energy, vol. 265, p. 114802, 2020.

[8] G. Q. Cui, Z. C. Shang, and D. Qin, "Stability analysis of seasonal frozen soil slope under cyclic freezing and thawing test," Journal of Yangtze River Scientific Research Institute, vol. 35, pp. 102-105, 2018.

[9] D. H. Rui, M. C. Ji, D. Nakamura, and T. Suzuki, "Experimental study on gravitational erosion process of vegetation slope under freeze-thaw," Cold Regions Science and Technology, vol. 151, pp. 168-178, 2018.

[10] H. J. Liu, Y. Guo, W. Shan, X. X. Tao, and Y. Y. Sun, "Instability of soil cutting slopes caused by freeze-thaw and reinforcement mechanism by vegetation," Chinese Journal of Geotechnical Engineering, vol. 33, pp. 1197-1203, 2011.

[11] G. D. Sun, X. G. Dong, W. T. Tian, and Y. B. Jie, "Stability calculation method of permafrost slopes supported by frame structures with anchors," Journal of Disaster Prevention and Mitigation Engineering, vol. 39, pp. 124-131, 2019.

[12] H. Y. Liu and T. C. Xie, "Numerical simulation of the mechanical behavior of rock mass with different scale flaws and its application," Arabian Journal of Geoscience, vol. 13, no. 6, 2020.

[13] J. Xu, X. Zheng, and H. Zhang, "Analysis on mechanism and stability of freeze-thaw spalling disease for slope in loess region," Journal of Xi'an University of Architecture \& Technology, vol. 50, pp. 477-484, 2018.

[14] J. Qian, Q. Yu, L. Guo, and J. Hu, "Experimental study on convection characteristics of crushed-rock layer," Canadian Geotechnical Journal, vol. 50, no. 8, pp. 834-840, 2013.

[15] Y. Wang, W. K. Feng, H. J. Wang, J. Q. Han, and C. H. Li, "Geomechanical and acoustic properties of intact granite subjected to freeze-thaw cycles during water-ice phase transformation in Beizhan's open pit mine slope, Xinjiang, China," Water, vol. 11, no. 11, p. 2309, 2019.

[16] Y. C. Zhang, R. Q. Huang, L. D. Zhao, R. H. Fu, and X. J. Pei, "Study of Tianshan slope rock mass rating(TSMR)system," Chinese Journal of Rock Mechanics and Engineering, vol. 29, pp. 617-623, 2010.

[17] Y. L. Chou, L. Y. Sun, B. A. Li, and X. L. Wang, "Effects of freeze-thaw cycle and dry-wet alternation on slope stability," Sciences in Cold and Arid Regions, vol. 11, pp. 159-172, 2019. 
[18] Y. L. Zhang, L. G. Zhou, J. Wang, C. L. Wu, and X. Lv, "Effects of freeze-thaw cycles on mechanical properties of silty sand and subgrade slope stability," Journal of Jilin University(Engineering and Technology Edition), vol. 49, pp. 1531-1538, 2019.

[19] G. C. Shi, X. J. Yang, and H. C. Yu, “Acoustic emission characteristics of creep fracture evolution in double-fracture fine sandstone under uniaxial compression," Engineering Fracture Mechanics, vol. 210, pp. 13-28, 2019.

[20] C. X. Wang, B. T. Shen, J. T. Chen et al., "Compression characteristics of filling gangue and simulation of mining with gangue backfilling: an experimental investigation," Geomechanics and Engineering, vol. 20, pp. 485-495, 2020.

[21] G. Feng, X. C. Wang, M. Wang, and Y. Kang, "Experimental investigation of thermal cycling effect on fracture characteristics of granite in a geothermal-energy reservoir," Engineering Fracture Mechanics, vol. 235, p. 107180, 2020.

[22] G. Feng, Y. Kang, and X. C. Wang, "Investigation on the failure characteristics and fracture classification of shale under brazilian test conditions," Rock Mechanics and Rock Engineering, vol. 53, no. 7, pp. 3325-3340, 2020.

[23] F. Q. Ren, C. Zhu, and M. C. He, "Moment tensor analysis of acoustic emissions for cracking mechanisms during schist strain burst," Rock Mechanics and Rock Engineering, vol. 53, no. 1, pp. 153-170, 2020.

[24] H. Y. Pan, D. W. Yin, N. Jiang, and Z. G. Xia, "Numerical simulation of the mechanical behavior of rock mass with different scale flaws and its application," Advances in Civil Engineering, vol. 13, no. 6, Article ID 8871335, pp. 1-13, 2020.

[25] J. Xu, G. L. Dai, W. M. Gong, Q. Zhang, A. Haque, and R. P. Gamage, "A review of research on the shaft resistance of rock-socketed piles," in Acta Geotechnica, pp. 1-25, 2020.

[26] J. Xu, A. Haque, W. Gong, R. P. Gamage, G. L. Dai, and Q. Zhang, "Experimental study on the bearing mechanisms of rock-socketed piles in soft rock based on micro X-ray CT analysis," Rock Mechanics and Rock Engineering, vol. 53, no. 8, pp. 3395-3416, 2020.

[27] J. Wang, Y. Zhang, Z. Qin, S. G. Song, and P. Lin, “Analysis method of water inrush for tunnels with damaged waterresisting rock mass based on finite element method-smooth particle hydrodynamics coupling," Computers and Geotechnics, vol. 126, p. 103725, 2020.

[28] J. T. Chen, J. H. Zhao, S. C. Zhang, Y. Zhang, F. Yang, and M. Li, "An experimental and analytical research on the evolution of mining cracks in deep floor rock mass," in Pure and Applied Geophysics, 2020.

[29] B. Chen, S. C. Shi, Y. Y. Li, Z. K. Li, and H. J. Zhou, "Physical simulation study of crack propagation and instability information discrimination of rock-like materials with faults," Arabian Journal of Geosciences, vol. 13, no. 18, 2020.

[30] Z. Shi, H. P. Tao, S. Z. Liu, B. T. Liu, and B. Guo, "Research of freeze-thaw erosion in the three-river-source area based on GIS," Transactions of the Chinese society of agricultural engineering, vol. 28, pp. 214-221, 2012.

[31] Y. F. Lu, T. Zhang, Y. Liu, Y. M. You, C. Feng, and W. H. Kong, "Evaluation and spatial distribution characteristics of freezethaw erosion intensity in the Yalu Tsangpo River basin on the basis of geographic information system," Geomatics Natural Hazards \& Risk, vol. 10, no. 1, pp. 1047-1069, 2019.

[32] S. S. Subramanian, T. Ishikawa, and T. Tokoro, "Stability assessment approach for soil slopes in seasonal cold regions," Engineering Geology, vol. 221, pp. 154-169, 2017.
[33] Y. H. You, Q. H. Yu, L. Guo et al., "In-situ monitoring the thermal regime of foundation backfill of a power transmission line tower in permafrost regions on the Qinghai-Tibet Plateau," Applied Thermal Engineering, vol. 98, pp. 271-279, 2016.

[34] K. Q. Liu, H. Y. Liu, and X. B. Qi, "Numerical study on longterm stability of soil-rock mixture slope using strength reduction technique," Journal of Engineering Geology, vol. 28, pp. 327-334, 2020.

[35] G. Cheng, Y. Lai, Z. San, and F. Jiang, "The 'thermal semiconductor' effect of crushed rocks," Permafrost and Periglacial Processes, vol. 18, no. 2, pp. 151-160, 2007.

[36] Y. S. Kang, C. C. Hou, B. Liu, Q. S. Liu, H. M. Sang, and Y. C. Tian, "Frost deformation and a quasi-elastic-plastic-creep constitutive model for isotropic freezing rock," International Journal of Geomechanics, vol. 20, no. 8, 2020.

[37] C. Zhu, Z. G. Tao, S. Zhao, and S. Yang, "V shaped gully method for controlling rockfall of high-steep slope in China," Bulletin of Engineering Geology and the Environment, vol. 78, pp. 2731-2747, 2019.

[38] M. E. Orakoglu, J. K. Liu, and F. J. Niu, "Experimental and modeling investigation of the thermal conductivity of fiberreinforced soil subjected to freeze-thaw cycles," Applied Thermal Engineering, vol. 108, pp. 824-832, 2016.

[39] M. Y. Zhang, W. S. Pei, S. Y. Li, J. G. Lu, and L. Jin, "Experimental and numerical analyses of the thermo-mechanical stability of an embankment with shady and sunny slopes in a permafrost region," Applied Thermal Engineering, vol. 127, pp. 1478-1487, 2017.

[40] F. J. Niu, G. D. Cheng, W. K. Ni, and D. W. Jin, "Engineeringrelated slope failure in permafrost regions of the Qinghai-Tibet Plateau," Cold Regions Science and Technology, vol. 42, no. 3, pp. 215-225, 2005.

[41] Z. G. Tao, Y. Wang, and C. Zhu, "Mechanical evolution of constant resistance and large deformation anchor cables and their application in landslide monitoring," Bulletin of Engineering Geology and the Environment, vol. 78, no. 7, pp. 4787-4803, 2019.

[42] H. Huang, T. Babadagli, X. Chen, H. Z. Li, and Y. M. Zhang, "Performance comparison of novel chemical agents for mitigating water-blocking problem in tight gas sands," SPE Reservoir Evaluation \& Engineering, vol. 1, pp. 1-9, 2020.

[43] D. Z. Ren, D. S. Zhou, and D. K. Liu, "Formation mechanism of the Upper Triassic Yanchang Formation tight sandstone reservoir in Ordos Basin-Take Chang 6 reservoir in Jiyuan oil field as an example," Journal of Petroleum Science and Engineering, vol. 178, pp. 497-505, 2019. 